\title{
ANDRÉS BELLO: EXPERIENCIA HISTÓRICA Y TRANSICIÓN CULTURAL*
}

\author{
Carlos Ossandón Buljevic** \\ Universidad de Chile \\ cob2002@hotmail.com
}

\begin{abstract}
Resumen
El artículo intenta precisar algunos de los rasgos principales de lo que se podría denominar la "experiencia histórica" bellista. Un tipo de "experiencia" que, enfrentada a una muy severa "crisis generalizada del sentido de las cosas", no es disociable del asentamiento de unas bases que buscan responder a los nuevos requerimientos histórico-culturales, sin por ello negar abruptamente el pasado.
\end{abstract}

Palabras Clave: Andrés Bello, experiencia histórica, transición cultural.

\section{Abstract}

The article attempts to clarify some of the main features of what might be called the "historical experience" bellista. A kind of "experience" that, faced with a very severe "generalized crisis of meaning of things", is not separable from the settlement of a foundation seeking to respond to new historical and cultural requirements, without denying abruptly the past.

KEY WORDS: Andrés Bello, historical experience, cultural transition.

$\overline{R A}$ "Es verdad que, a veces, el cambio histórico se hace sentir con una intensidad dramática en individuos que -como Maquiavelo y Guicciardini- han sido particularmente sensibles a ello, ya que han experimentado en sí mismos el ser como Atlas cargando sobre sus hombros el peso total del pasado y del presente" (Frank Ankersmit, Experiencia histórica sublime. Traducción de Luis Gueneau de Mussy, Chile: Palinodia, 2008, p. 21).

* Este artículo forma parte de la primera etapa del proyecto Fondecyt $\mathrm{N}^{\circ} 1085029$.

** Doctor en Filosofía. Profesor Universidad de Chile. 
I. No es ciertamente novedoso afirmar que Andrés Bello se sitúa en una particular coyuntura histórica, en una intersección de mundos, en un período de transición cultural y política que va a tener importantes consecuencias para América Latina. Juan Durán Luzio llama precisamente la atención sobre este hecho, recordando que, entre fines del siglo XVIII y el siguiente siglo, es la vida misma del continente la que va a cambiar. Una "época de transición", dice, que no finaliza con la Independencia de España como no es tampoco, agrego, exclusiva de América ${ }^{1}$. La Revolución francesa de 1789, la independencia de las trece colonias inglesas, la revolución industrial británica, el desmembramiento del imperio español, el propio proceso de ruptura con España y la consiguiente construcción de los Estados nacionales en América Latina, sin dejar de mencionar unas emergencias que desordenan los contornos de las letras, de la sensibilidad o del gusto, son parte importante del espacio temporal o cambiante que vive Bello. Sin embargo, para Luis Bocaz, no es solo la "transición” el signo que marca la larga vida de Bello sino también la conciencia que posee del carácter de esta época de "crisis", un rasgo éste último que aquilata su particular sensibilidad histórica, emplazada en el "umbral" de importantes mutaciones, entre los siglos XVIII y XIX, en las postrimerías de una época y el inicio de otra ${ }^{2}$. Su participación en la discusión sobre el papel desempeñado por España en América o sobre la forma cómo se debía asumir el legado o la tradición, su temprano interés por redactar un resumen de la historia de Venezuela, así como sus alcances sobre el modo de escribir y de estudiar la historia, revelan algunas de las facetas de una sensibilidad que se alimenta de fuentes europeas.

Cierto es que, desde distintas perspectivas o planos, se podría matizar este modo de ver las cosas, destacando el carácter convencional o rutinario de los conceptos de "transición" o de "crisis"; o haciendo valer las razones de una historiografía que se apoya en un concepto de la historia que confía más en las continuidades que en los cortes; o trayendo a colación los diagnósticos de Francisco Bilbao, por ejemplo, quien bastante después de la Independencia todavía insiste en el objetivo de la "desespañolización de América".

Como quiera que sea, es difícil negar que, para actores importantes del período, desde las primeras décadas del siglo XIX, emergen unas expectativas y problemas, impensables bajo las condiciones del régimen colonial, que ya no se explican recurriendo a la lógica de los corsi e ricorsi o que buscan un modo de validación que se sostiene en la diferencia que genera la irrupción de una determinada y, sobre todo, inédita “experiencia histórica" en América Latina. Como si los acontecimientos que se precipitan bajo las nuevas condiciones hubiesen hecho repentinamente visible nuestra capacidad de hacedores de la historia; una historia que se presenta ahora menos dependiente de factores ajenos a la voluntad de los hombres o menos atada a unas resignaciones, providencias o servidumbres que no hacía mucho hegemonizaban una visión que se fraguaba en las alturas. Algunos de los rasgos generales que prefiguran esta peculiar

Juan Durán Luzio 1999, p. 13.

Luis Bocaz 1981. 
"experiencia histórica" tienen que ver precisamente con el espesor hasta ese momento desconocido que toman los sujetos de la historia, el nuevo papel que se le concede a la libertad o a la voluntad en la propia dirección del curso histórico y la valorización que adquieren las transformaciones mismas, abiertas ahora a una percepción más secularizada de las cosas.

Me atrevería a señalar que en estos puntos la "derrota" de José Victorino Lastarria es más subjetiva que real. Lastarria erró menos de lo que él mismo creyó. Manifiestamente tocado por las críticas que realizó Bello a la memoria histórica que leyó en el primer aniversario de la Universidad de Chile en 1844 (a las que se unieron las del periodista argentino Miguel Piñero publicadas en El Mercurio de Valparaíso ese mismo año), y más adelante por el informe universitario redactado por Antonio Varas y Antonio García Reyes a propósito de una nueva obra histórica que presentó en 1847, seguido por las contundentes críticas que Bello realizó al profesor de historia del Instituto Nacional, Jacinto Chacón, quien había asumido la defensa de su historia "filosófica", Lastarria quedó obnubilado por este vendaval que le cayó encima y por la "historia casera" que, según él, había prevalecido en la historiografía nacional. No logró percibir, como se comprueba algo dramática o teatralmente en sus Recuerdos literarios (1878), que los principios que había venido elaborando (la importancia de la "voluntad" y de la "libertad", la perspectiva del "progreso", la crítica a una historia sometida a leyes "providenciales" o "metafísicas"), más que ciertos aspectos puntuales de la polémica (la historia como fuente de aprendizaje y no como simple testimonio, la crítica al narrativismo historiográfico), se estaban haciendo carne, en ese mismo período, en los distintos protagonistas de su época, incluso en aquellos que lo combatían, que no parecían dispuestos a dejarse llevar por el curso natural de las cosas ${ }^{3}$.

La sensibilidad emergente, sujeta a distintas retóricas, formalidades discursivas y visiones del curso histórico: en algunos casos concebido más directo y ascendentemente (Lastarria), en otros, bajo un modelo más integrador o recuperativo (Bello), se nutre - dicha sensibilidad- de una serie de tópicos que Bello a su modo comparte: la creencia de que los conocimientos se perfeccionan con el tiempo como también los soportes y códigos de la comunicación; la propia idea de "progreso" que comienza a ser ampliamente usada por no pocos autores del período y también por Bello; el carácter ejemplar que toma en esta perspectiva el proceso independentista como tal, percibido como expresión de esa "acción" o "voluntad” que destacó Lastarria; las relaciones entre los principios universales que guían la historia y las realizaciones particulares de estos

3 Se ha dicho que las consecuencias de la presente polémica y, en particular, el "triunfo" de Bello sobre Lastarria, o del método ad narrandum sobre el ad probandum, determinaron "el porvenir de la historiografía chilena" (Guillermo Feliú Cruz). Tanto la problematización de esta última aseveración, como el reexamen de las confrontaciones que se dieron en la década de 1840 se presentan como dos interesantes puntos de referencia para la discusión más actual. La polémica se inicia con las reacciones que suscitó el arribo a Chile, desde París, de los primeros productos de la Historia física y política de Chile, del naturalista francés Claudio Gay, trabajo respaldado por Bello. 
principios; las posibilidades de intervenir o conducir un tiempo que no solo mutaba sino también se acercaba a su cumplimiento o a su ley, en la línea que señalaban Herder, Hegel o Cousin. Todos estos tópicos configuran el marco conceptual de esa "intensidad dramática" que Ankersmit reconoce en individuos sensibles al cambio histórico, como Maquiavelo o Guicciardini, y que también hemos creído reconocer en Bello. La imagen de un Atlas que se experimenta a sí mismo cargando "sobre sus hombros el peso total del pasado y del presente", según continúa Ankersmit, es corroborada no solo por Luis Bocaz sino también por Antonio Cussen, para quien los poemas de Bello, sobre todo aquellos escritos en los convulsionados tiempos de la revolución, en Londres, son "una respuesta intensa a una crisis generalizada del sentido de las cosas"; una respuesta que se hace cargo de la tensión entre el pasado y el presente y que, en lugar de rehuir esta tensión, o de refugiarse obstinadamente en lo perimido, repone o reformula -en un gesto sin duda audaz- las prerrogativas de una voz clásica en un mundo que "subvierte inexorablemente todos los principales baluartes de la cultura clásica"4.

En comparación con otros actores del período, enfrascados en perspectivas históricas más lineales, dicotómicas y escasamente dubitativas, en Bello las tensiones o contraposiciones de época se presentan más patente y dramáticamente. Si bien esta comparación se podría matizar, mostrando, por ejemplo, cómo en el Facundo (1845) de Domingo Faustino Sarmiento la fuerza expresiva o estética tan manifiesta en la descripción de la "barbarie" tiende a desestabilizar el horizonte "civilizador", desbordando de esta manera los límites de una razón estrechamente dualista, es claro que en Bello, enfrentado a otro tipo de tensiones, más propiamente culturales que sociológicas, estas mantienen sus aristas propias, no se exponen como polos irreconciliables y logran unas síntesis o unos equilibrios que no están en Sarmiento. Lejos del propósito de negar rápidamente la tradición para enseguida superponer lo nuevo, actitud bastante recurrente, según Leopoldo Zea, en el liberalismo decimonónico ${ }^{5}$, lo que se constata en Bello es la búsqueda o la instauración de unas bases que no rompen abruptamente el diálogo con el pasado y que se nutren o tienen como punto de partida esa "crisis generalizada del sentido de las cosas" que destaca Antonio Cussen. Es precisamente una "crisis" de esta magnitud la que va a definir y precipitar, según nuestro punto de vista, los demás rasgos de la "experiencia histórica" que examinamos ${ }^{6}$. Esta experiencia-crisis incluye a la política y a sus fundamentos, supone el agotamiento de la monarquía absoluta y también de la constitucional, así como la exploración por la nueva matriz republicana, pero también trasciende la esfera política, asociándose a la remoción de cimientos epocales generales y, más específicamente, a la desestabilización de los parámetros propios de la cultura virreinal. Todo esto va a plantear, aunque no solo en Bello,

Antonio Cussen 1998, pp. 10-11.

Leopoldo Zea 1949.

El rol de las "crisis" es valorado por Bello en uno de sus textos. Las "crisis", dice, "despiertan la atención del espíritu humano", ensanchan "la esfera de los conocimientos" y mediante las lecciones de la "experiencia" se aprende "a juzgar por sí mismo". "Estudios sobre Virgilio, por P. F. Tissot", 1826, en Andrés Bello 1985, pp. 261 y 262. 
desafíos no menores, básicos o fundacionales, para un continente que recién empezaba a percatarse, conducido por el espíritu iluminista de Alexander von Humboldt, el Abate Molina, el propio Bello de las "Silvas" y Claudio Gay más tarde, que tenía un cuerpo físico, una geografía, una flora y una fauna que le daban una palpable singularidad ${ }^{7}$.

II. Se podría discutir si lo que venimos diciendo cristaliza solo en una lectura sociocultural del presente, no exenta de consideraciones históricas, o se está sobre todo delante de un tipo de "experiencia" que trae aparejada no pocas sacudidas en el ámbito de la "subjetividad”, y cuya sensibilidad o apertura histórica, tributaria del historicismo romántico y de las transformaciones que en los siglos XVIII y XIX afectan al mundo occidental y también a América Latina, podemos reconocer o tildar de "moderna". Inclinados por esta última opción, es preciso aceptar que la modernidad de la "experiencia" bellista es bastante peculiar, dado que ella no se realiza introduciendo rupturas dramáticas o en la radicalización de los desapegos con el mundo tradicional, tal como suelen operar otros modernismos. Sin embargo, como se ha hecho notar en otra parte, la actitud moderna no es tan solo asimilable a ruptura. En este caso, es el persistente juego entre ruptura y continuidad, la mantención de las tensiones que presentan estos dos polos $\mathrm{y}$, sobre todo, el decidido e ingente esfuerzo por crear, paradójicamente quizá, nuevas tradiciones (en el lenguaje, en las regulaciones de la sociedad civil, en la educación universitaria) lo que define la novedad o modernidad de la "experiencia" bellista.

Junto a esta primera consideración, una segunda se hace necesaria. Ella podría ser prescindible si no fuese importante para una adecuada caracterización de la "experiencia" que examinamos: Bello no siempre es el mismo; el venezolano no exhibe un emplazamiento inamovible, siempre igual, capaz de proyectarse sin más sobre el mundo real.

Una visión de este tipo pasa por alto los tres lugares de permanencia que algunos trabajos han venido destacando como un modo de clasificar y diferenciar la praxis bellista: el Bello-Caracas (1781-1810), el Bello-Londres (1810-1829) y el Bello-Santiago de Chile (1829-1865). Se puede sostener, por ejemplo, dejándonos llevar por esta taxonomía, que en contraste con sus dos primeras permanencias, la última da cuenta de un sujeto de discurso que trae posicionamientos nuevos y que no es siempre completamente la consecuencia lógica del o de los sujetos discursivos anteriores. Sin desencajar del todo esta nueva posición de las anteriores, es plausible señalar que son otras las condiciones, las modalidades de enunciación o el campo de posibilidades que rigen al nuevo sujeto que opera en Chile. En el lenguaje de Luis Bocaz, en Chile, Bello efectúa el tránsito de la "especulación abstracta" del período londinense a la "práctica concreta"; solo aquí, continúa, "la teoría cultural se viste con la ropa de trabajo de la política cultural" 8 . Es

7 Sobre el descubrimiento del cuerpo físico del continente americano, ver Mario Berríos y Zenobio Saldivia 1995.

$8 \quad$ Luis Bocaz, op. cit., p. 19. 
precisamente en este punto -nos referimos a la notable predisposición política, ingenieril y transformadora de la obra de Bello en Chile- que radica su marcada diferencia con otros empeños, más cautivos de sus ensoñaciones que de la capacidad realizadora de la voluntad. La figura prototípicamente románica y libertaria de Francisco Bilbao, con su pelo al viento y sus deseos de épater, parece ser la contraparte más nítida de la consistente y también arrolladora praxis bellista.

Es claro, en la dirección que queremos avanzar en este apartado, que su "concepto" político no siempre responde a la misma matriz, que éste no preexiste a los hechos, que no es asimilable al modelo platónico, y que hace patente, en consecuencia, ciertas variaciones y vacilaciones, aunque también la permanencia de rasgos o tendencias importantes 9 . No es casual, entonces, el interés de Martín Bernales por los cambios, matices o ambivalencias que enseñan las alternativas políticas en Bello, desde su inicial servicio a la monarquía española hasta su adhesión a la idea republicana ${ }^{10}$. Por otro lado, su "concepto" literario, si bien muy sensible o naturalmente inclinado hacia los modelos clásicos de la literatura greco-latina y española, tampoco es inamovible ni insensible a las escuelas más recientes y no puede ser asimilado sin más al anti-romanticismo, tal como lo probó Emir Rodríguez Monegal ${ }^{11}$.

Lo dicho no significa que no haya también aspectos fundamentales que cruzan prácticamente toda la obra de Bello. En rigor, lo que vemos no son solo distintas articulaciones o cristalizaciones histórico-discursivas, algunas más incipientes otras más maduras, sino también unas tendencias o unas predominancias que atraviesan prácticamente toda su obra configurando un perfil. Llama la atención, en esta línea, el modo como se combina, no siempre de la misma manera o con el mismo grado de penetración, lo más coyuntural y cambiante con aspectos más permanentes, arrojados al tiempo largo. Respecto de esto último, estamos pensando principalmente en esa arremetida ingenieril y "fundacional" que ciertamente no somos los primeros en percibir

9 Hemos puesto "concepto" entre comillas como un modo de recordar el insistente esfuerzo de Bello por validar ciertas voces y corregir otras. En la polémica que sostiene con José Joaquín de Mora en 1830, Bello busca desterrar la voz "concepción”, que "no es la palabra propia para exprimir la idea concebida por el entendimiento". Una polémica particularmente iluminadora de la conexión que mantiene el venezolano con la filosofía moderna, en su caso más tributaria de Locke y de Cousin que de Kant. En ella niega el acceso a las "esencias" de las cosas dado que estas son inaccesibles a la razón. Al respecto, dice: "cabalmente una de las cosas que caracterizan a la filosofía moderna y la distinguen de la jerigonza escolástica, es el haber trazado con precisión los límites de la razón humana”. Si bien hay ciertas dudas de la paternidad de Bello sobre determinadas partes de los textos de la polémica, en especial de sus aseveraciones políticas, tiende a aceptarse su conformidad respecto de lo sustancial dicho en ella. La presente polémica se puede seguir con sus aclaratorias notas en la selección ya citada: Andrés Bello, op. cit., pp. 312 a 332. Un análisis bastante completo de la misma, que incluye los documentos de época, en Alamiro de Ávila Martel 1982.

10 Martín Bernales 2009. Antonio Cussen, por su parte, define a Bello en los tiempos de la revolución como "el hombre que vacila", op. cit., p. 90.

$11 \quad$ Emir Rodríguez Monegal 1969. 
como uno de los sellos más distintivos del venezolano. Es importante indicar que la dialéctica recién descrita permite distintas confluencias discursivas: la literatura con la política, la gramática con el derecho; confluencias no extrañas a esa indiferenciación propia del período anterior a la futura constitución de campos o saberes diferenciados ${ }^{12}$.

III. Una manifestación paradigmática de lo que estamos insinuando, del modo como se conjugan los factores más permanentes con los más circunstanciales, se da en el Discurso pronunciado por Bello en la instalación de la Universidad de Chile, el día 17 de septiembre de 1843. Como se sabe, en este célebre Discurso, Bello afirmó en tres ocasiones: "todas las verdades se tocan". Detengámonos brevemente en este enunciado.

En una primera aproximación, éste parece operar como un "trascendental", una condición primera o un a priori, capaz de concentrar o de resumir el componente esencial de la política cultural y universitaria bellista. El presente enunciado busca armonizar el cultivo de las ciencias y las letras con los puntos de vista de la moral y de la política. Bello señala, además, que los "adelantamientos" en todas estas líneas "se llaman unos a otros, se eslabonan, se empujan”. Habría, pues, un movimiento progresivo, también civilizador, que compromete en su relación a estas distintas "verdades" que se propagan. Bello es aquí tributario de una idea de progreso, secular o moderna, que reemplaza a la resignación medieval y que tiene como fuentes las aperturas de la ilustración europea del siglo XVIII. Pero Bello da un paso más al subrayar que habría una "alianza estrecha" y no una "antipatía secreta" entre religión y letras (o ciencias).

Es preciso advertir que el espíritu progresista e integrador del enunciado que examinamos, tributario más particularmente del eclecticismo anglo-francés ${ }^{13}$, establece, en el texto de marras, correlaciones con un determinado concepto del "alma" o de las "facultades humanas", afectadas por la misma dinámica que envuelve a las "verdades", como también, en otro texto, con el modo como Bello entiende la "verdad" como tal, no ajena a la armonía ${ }^{14}$.

En una segunda aproximación, se puede correlacionar el presente enunciado con ciertas exigencias políticas y culturales propias de un país que, en el convulsionado período de la post-independencia, carecía de formas y de consensos estables. Algo más allá, entonces, de la pertinencia filosófica y universitaria de este espíritu integrador o

12 Acerca de la relación entre literatura y política (más particularmente, entre clásicos, románticos y la política legitimista y liberal) se puede consultar un distante o desaprensivo texto de Bello, un poco antes de que la célebre polémica literaria de 1842 lo obligue a actuar con más cuidado. Nos referimos a Juicio crítico de don José Gómez Hermosilla, 1841/1842, en Obra Literaria. Respecto de la segunda relación, y la perspectiva normativa que comparten, ver Jaime Concha 1997, p. 26.

13 Cfr. Carlos Ruiz y Cecilia Sánchez 1991.

14 Andrés Bello, "Análisis ideológica (sic) de los tiempos de la conjugación castellana”, Obra Literaria 1841. 
conciliador es posible vincular dicho espíritu con la búsqueda de unos acuerdos en el plano cultural que parecían indispensables para la creación de una cierta figura de país en Chile. En este sentido apunta precisamente Carlos Ruiz Schneider, para quien este "deseo de conciliación" corresponde a la "voluntad de producir, en este caso, en el terreno cultural, la alianza entre los nuevos intelectuales chilenos y los intelectuales tradicionales"; una alianza que supondrá la exclusión de aquellos que planteaban unas opciones más consecuentes con sus postulados. "Es aquí claro -continúa Ruiz- que la conciliación que Bello propone, no puede desde luego dejar contentos, ni a los espíritus escolásticos - que no tienen nada que hacer con un sistema de las facultades humanas, propuesto como fundamento de la religión-, ni a los partidarios de la Ilustración que no entienden por qué los principios de la razón o de la experiencia tengan que admitir verdades que vienen desde fuera de estos dos principios, los únicos legítimos, del saber" 15 .

Sin embargo, y ésta es la tercera aproximación, se puede advertir que, a la luz de las bases que Bello asienta en su Discurso, lo que se presenta ante nuestros ojos es también un pathos de tipo fundacional que no se reduce a la construcción de un determinado horizonte político; que estas bases, expuestas en muchos otros textos y no solo en su Discurso, y haciendo valer una multiplicidad de registros, dejan entrever un cierto ethos o modelo cultural y público de largo alcance, una "cultura", en suma: a) "ilustrada", por la confianza que deposita en las "luces" y en el desarrollo mancomunado de los saberes y b) "letrada", por la confianza que deposita en el desarrollo de las letras y de la escritura, concebidas como bases o condiciones de la moral, de la política y de un espacio público en formación.

En suma, en una circunstancia muy particular, en el año de la inauguración de la Universidad de Chile, y cuando el liberalismo, o la oposición a los gobiernos portalianos, comenzaba a mostrar una capacidad de recuperación que ya no será posible desatender más, Bello crea, animado por la urgencia de dar forma o de constituir un "mundo", un texto que no es separable de las relaciones de fuerzas existentes, pero que supone a la vez una transformación de las mismas, apartándose de las formas de validación, rutinas o prestigios propios de la cultura virreinal. La embestida bellista es algo más que una decisión aislada, no compromete tan solo a la Universidad como institución, ni tampoco se reduce, globalmente considerada, al levantamiento de superestructuras útiles para el funcionamiento de la llamada "República Autoritaria" en Chile ${ }^{16}$. Es más grave o importante que todo eso. Ella se asocia, en el lenguaje punzante de Michel Foucault, a "una dominación que se debilita, se distiende, se envenena a sí misma /y a/ algo distinto que aparece en escena, enmascarado"17. Representa, como hemos

15 Carlos Ruiz 1975, pp. 35 y 36.

16 Una caracterización del régimen político que se inicia con la Constitución de 1833, "republicano en las formas y autoritario en la práctica", así como el señalamiento del carácter precursor que tiene el "hiper-presidencialismo" en Bello, que se destaca como "el rasgo principal de la forma política constitucional chilena", se encuentra en Renato Cristi y Pablo Ruiz-Tagle 2006, pp. 93 a 99.

17 Michel Foucault 1980, p. 20. 
visto, un muy elaborado o sutil juego entre el eclecticismo filosófico, determinadas exigencias consensuales en el ámbito político-institucional y el establecimiento de bases culturales de largo aliento. Esta última dimensión no es menor y tiene como centro o aspiración última el requerimiento ilustrado de aprender a "pensar por sí", dice Bello en su Discurso. En el esfuerzo por no contentarnos con unos resultados que nos dispensen "del examen de sus títulos" o con unos teoremas que nos liberen del "trabajo intelectual de la demostración", Bello invita a una larga y difícil tarea. Ella se refiere a la constitución de un lugar cultural propio, en cuyo desarrollo es central la relación con otros lugares culturales. Esta dimensión, que no siempre se manifiesta del mismo modo (más embrionaria en la década de 1830, más decidida en la década de 1840), traspasa y a la vez organiza distintos o particulares momentos o coyunturas en Bello, desbordando en este sentido el marco del Discurso recién examinado, constituyendo así una de las "experiencias” más importantes del universo bellista.

Terminemos señalando que, enfrentado a muy complejos y nuevos problemas políticos y culturales, cuestión que comprometió en su tiempo con distintos resultados no solo a su país de adopción, Bello va a movilizar todo su capital intelectual, impulsado por un contexto de crisis de los referentes culturales o simbólicos tradicionales y sin tener a la mano respuestas hechas. De esto dan cuenta tanto sus trabajos y sus días como su acendrado sentido de ubicación histórica. No sabemos si Bello logró visitar en vida esos valles solitarios del Erebo que destaca en su poema El Anauco, pero sí es claro que la magnitud de las exigencias, los pesos que tuvo que sobrellevar, hacen identificable en ella esa "intensidad dramática" que Ankersmit reconoce en individuos sensibles a los requerimientos históricos.

\section{Referencias bibliográficas}

Bello, Andrés (1841), Obra Literaria, Selección y prólogo de Pedro Grases, Biblioteca Ayacucho, Caracas, 1985, pp. 261 y 262.

Bernales, Martín (2009), "El republicanismo de Bello en Chile”, Mapocho. Chile: Dibam, n. 66.

Berríos, Mario y Zenobio Saldivia (1995), Claudio Gay y la ciencia en Chile. Santiago de Chile: Bravo y Allende Editores.

Bocaz, Luis (1981), “Andrés Bello: política cultural y formación social dependiente”, Doscientos años de Andrés Bello. Araucaria de Chile, Madrid: Fuenlabrada.

Concha, Jaime (1997), "Gramáticas y códigos: Bello y su gestión superestructural en Chile”, Mapocho. Santiago: Ediciones de la Biblioteca Nacional de Chile, n. 42, segundo semestre, p. 26.

Cristi, Renato y Pablo Ruiz-Tagle (2006), La República en Chile.Teoría y práctica del Constitucionalismo Republicano. Santiago de Chile: Lom Ediciones, pp. 93 a 99.

Cussen, Antonio (1998), Bello y Bolívar. México: Fondo de Cultura Económica, pp. 10 y 11 . 
de Ávila Martel, Alamiro (1982), Mora y Bello en Chile (1829-1831). Santiago: Ediciones de la Universidad de Chile.

Durán Luzio, Juan (1999), Siete ensayos sobre Andrés Bello, el escritor. Santiago de Chile: Editorial Andrés Bello, p. 13.

Foucault, Michel (1980), "Nietzsche, la genealogía, la historia", Microfísica del poder. Madrid: Las Ediciones de La Piqueta, p. 20.

Rodríguez Monegal, Emir (1969), El otro Andrés Bello. Caracas: Monte Ávila Editores.

Ruiz, Carlos (1975), "Moderación y Filosofía (Notas de investigación sobre la filosofía de Andrés Bello)", Teoría. Universidad de Chile, Sede Santiago Norte, ns. 5/6, pp. 35 y 36 .

Ruiz, Carlos y Cecilia Sánchez (1991), "L'eclectisme cousinien dans le travaux de Ventura Marín et d'Andrés Bello", Corpus. París: ns. 18/19.

Zea, Leopoldo (1949), Dos etapas del pensamiento en Hispanoamérica. Del romanticismo al positivismo. México: Fondo de Cultura Económica. 